Case Reports in
Gastroenterology
Case Rep Gastroenterol 2021;15:108-114

DOI: $10.1159 / 000510210$

Published online: February 1, 2021 (c) 2021 The Author(s)

Published by S. Karger AG, Base www.karger.com/crg

This article is licensed under the Creative Commons Attribution-NonCommercial 4.0 International License (CC BY-NC) (http://www.karger.com/Services/OpenAccessLicense). Usage and distribution for commercial purposes requires written permission.

\title{
Cystic Pancreatic Neuroendocrine Tumor in a Patient with Neurofibromatosis Type 1
}

\author{
Hiroharu Shinozaki $i^{a}$ Yuuichi Sasakura $^{a}$ Satoshi Shinozaki ${ }^{\text {b c }}$ \\ Toshiaki Terauchi $^{\text {a Junichi Matsui }}{ }^{d} \quad$ Kenji Kobayashi ${ }^{\mathrm{a}}$ \\ Alan Kawarai Lefor ${ }^{\mathrm{e}}$ Yoshiro Ogata ${ }^{\mathrm{a}}$ \\ ${ }^{a}$ Department of Surgery, Saiseikai Utsunomiya Hospital, Utsunomiya, Japan; ${ }^{b}$ Shinozaki \\ Medical Clinic, Utsunomiya, Japan; 'Division of Gastroenterology, Department of \\ Medicine, Jichi Medical University, Shimotsuke, Japan; dDepartment of Surgery, Tokyo

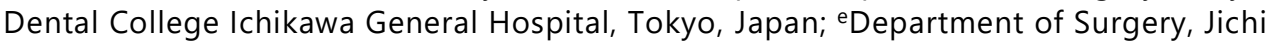 \\ Medical University, Shimotsuke, Japan
}

\section{Keywords}

Neurofibromatosis · Neuroendocrine tumor - Intrapancreatic mucinous neoplasm · Pancreatic tumor · von Recklinghausen disease

\begin{abstract}
Neurofibromatosis type 1 (NF-1) is strongly associated with neurofibromas and malignancies. Solid pancreatic neuroendocrine tumors (PanNETs) have been recently reported in patients with NF-1. PanNETs are always solid and rarely present with a cystic appearance due to central necrosis and hemorrhage caused by rapid growth. A 33-year-old female diagnosed with NF-1 at age 16 was referred for evaluation of a pelvic mass found on abdominal ultrasound. Magnetic resonance imaging showed a $6 \mathrm{~cm}$ solid pelvic mass adjacent to the left external iliac artery, and contrast-enhanced computed tomography scan showed a 3-cm solid para-aortic mass and a $3-\mathrm{cm}$ cystic mass in the pancreatic tail. Endoscopic ultrasonography showed a cystic tumor with necrotic tissue and septa. Preoperative diagnosis was pancreatic cystic malignancy with para-aortic lymph node metastasis accompanied with a pelvic neurofibroma. These lesions were resected simultaneously. The specimen resected from the pancreas showed a necrotizing cystic tumor invading abutting lymph nodes. Immunohistochemical analysis
\end{abstract}

\begin{tabular}{ll}
\hline & Satoshi Shinozaki \\
Shinozaki Medical Clinic \\
$6-1-13$ Kiyoharadai \\
Utsunomiya, Tochigi, 321-3223 (Japan) \\
shinozaki-s@aqua.ocn.ne.jp
\end{tabular}




\section{Case Reports in Gastroenterology}

Case Rep Gastroenterol 2021;15:108-114 DOI: $10.1159 / 000510210$

(c) 2021 The Author(s). Published by S. Karger AG, Basel www.karger.com/crg

Shinozaki et al.: PanNET Complicated by Neurofibromatosis Type 1

showed positive chromogranin A and synaptophysin. The Ki-67 index was $<1 \%$, and the mitotic count was $1 / 10$ in high power field. Therefore, a non-functional PanNET (grade G1) was diagnosed. The pelvic and para-aortic tumors were both neurofibromas. A cystic appearance is atypical for PanNET and makes preoperative diagnosis difficult. To the best of our knowledge, this is the first report of a cystic PanNET in a patient with NF-1.

(C) 2021 The Author(s)

Published by S. Karger AG, Basel

\section{Introduction}

Neurofibromatosis type 1 (NF-1) was first reported in 1882 as von Recklinghausen's disease, and the responsible gene was identified in 1990 [1]. NF-1 is a hereditary disorder due to a mutation of chromosome 17 (17q11.2) encoding neurofibromin, and its frequency is $1 / 3,000$ [2]. The risk of cancer in patients with NF-1 is 2.7 times higher than in the general population, and the cumulative risk is $20 \%$ by age 50 years [3]. The prevalence of gastrointestinal stromal tumors is comparatively high in patients with NF-1 [4]. However, pancreatic neuroendocrine tumors (PanNET) in patients with NF-1 are rare.

Generally, PanNETs represent 2\% of pancreatic tumors, and 48\% of PanNETs are nonfunctional [5]. PanNETs are always solid and rarely present with a cystic appearance due to central necrosis and hemorrhage caused by rapid growth. We report a nonfunctional PanNET with a cystic appearance accompanied by abdominal neurofibromas in a patient with NF-1.

\section{Case Report}

A 33-year-old female diagnosed as having NF-1 at age 16 was referred for evaluation of a pelvic mass found on abdominal ultrasound. Magnetic resonance imaging showed a $6-\mathrm{cm}$ solid pelvic mass adjacent to the left external iliac artery, and contrast-enhanced computed tomography (CT) scan showed a 3-cm solid para-aortic mass, suggestive of lymph node metastases (Fig. 1). Abdominal dynamic CT scan showed a 32-mm cystic mass in the pancreatic tail (Fig. 2). Endoscopic ultrasonography (EUS) showed a cystic tumor with necrotic tissue and septa (Fig. 2). EUS-guided fine needle aspiration was not attempted because the surgical resection strategy would not be changed by the results of aspiration cytology. The risk of tumor dissemination and peritoneal bleeding after needle aspiration was greater than any potential benefit. The preoperative diagnosis was mucinous cystic neoplasm, solid-pseudopapillary neoplasm of the pancreas or pancreatic cystic carcinoma with para-aortic lymph node metastases accompanied by a neurofibroma in the left pelvis. Therefore, these lesions were resected simultaneously. The resected specimen of the pancreas showed a necrotizing cystic tumor invading abutting lymph nodes (Fig. 3). Immunohistochemical analysis was positive for chromogranin A and synaptophysin. The Ki-67 index was $<1 \%$, and the mitotic count was $1 / 10$ in high-power field (Fig. 3). Hormone-related staining was negative for glucagon, somatostatin, gastrin, pancreatic peptide, and vasoactive intestinal peptide staining except for minimally positive insulin staining. She did not have any clinical manifestations to suggest an insulinoma. Therefore, a non-functional PanNET (grade G1) was diagnosed. The diagnosis of both the pelvic and paraaortic tumors was neurofibroma due to NF-1 (Fig. 4). Adjuvant therapy such as octreotide was not given postoperatively because of the low malignant potential of PanNET and the absence

\section{Karger'=}




\section{Case Reports in Gastroenterology}

Case Rep Gastroenterol 2021;15:108-114

DOI: $10.1159 / 000510210$

(c) 2021 The Author(s). Published by S. Karger AG, Basel www.karger.com/crg

Shinozaki et al.: PanNET Complicated by Neurofibromatosis Type 1

of metastatic lesions. After 7 years of postoperative follow-up, the patient is doing well and is disease-free.

\section{Discussion}

Hereditary disorders with the potential to develop PanNET include multiple endocrine neoplasia type 1, von Hippel-Lindau disease, tuberous sclerosis complex, and NF-1 [6]. The NF-1 germline mutation is believed to contribute to the development of these endocrine tumors. NF-1 is an autosomal dominant hereditary disease and prone to develop neoplasms including neurofibroma, pheochromocytoma, and gastrointestinal stromal tumor. Lack of function of neurofibromin, due to the gene responsible for NF-1, releases Ras protein suppression resulting in inappropriate cellular proliferation and activation of phosphoinositide-3 kinase pathway and mammalian target of rapamycin leading to inhibit cellular apoptosis [7]. Although solid PanNETs in patients with NF-1 have been reported, cystic PanNET has not been previously reported. In the present patient, it was difficult to establish the diagnosis of PanNET preoperatively because it presented with a cystic appearance with a para-aortic mass suggesting pancreatic cystic carcinoma with lymph node metastases. Since no definite medical treatment is established for the treatment of neurofibromas and malignant-like pancreatic tumors, we considered that surgical resection was the best strategy to improve the long-term outcome of the patient.

Only 8 patients with PanNET complicated by NF-1 have been reported since 1964 [8-15]. Their age varied from 28 to 62 years. The tumor size in the present patient ( $45 \mathrm{~mm}$ ) is the largest yet reported. Previously reported tumors ranged from 15 to $40 \mathrm{~mm}$. Four of the eight previously reported lesions (50\%) showed insulin positive staining $[8,10,13,15]$, and the present lesion also showed minimally positive staining for insulin. So far, there are no reports documenting a lesion with a cystic appearance.

Only $13-17 \%$ of PanNETs are cystic lesions. Cystic PanNETs tend to be larger but have a better prognosis compared to solid PanNETs [16]. The rates of recurrence, metastases and death are very low after resection in patients with cystic PanNETs [17]. The present patient had "worrisome features" according to international guidelines including a thickened wall with mural nodules and $>3 \mathrm{~cm}$ in diameter [18]. Therefore, surgical treatment is the first choice for treatment, but we were not able to predict the pathological diagnosis before surgery. The preoperative diagnosis of patients with cystic PanNET is frequently incorrect but undoubtedly important because the mortality and complications of surgical intervention involving the pancreas such as pancreatoduodenectomy are more invasive compared to other abdominal resections. EUS-guided fine-needle aspiration cytology is a viable option to assist in establishing the preoperative diagnosis, and the diagnostic yield is estimated as high as $77 \%$ by cytology [19]. Since surgical resection is inevitable regardless of the results of cytologic evaluation, we did not attempt aspiration cytology. Somatostatin receptor scintigraphy or somatostatin receptor positron emission tomography may be helpful to estimate the distribution of PanNETs preoperatively and to consider the possibility of postoperative therapy such as somatostatin analog therapy, peptide receptor radionuclide therapy or other modalities.

PanNETs in patients with NF-1 are comparatively rare. The cystic appearance is considered to be caused by central necrosis and bleeding due to rapid tumor growth. The cystic appearance is not typical for PanNETs and makes preoperative diagnosis difficult. To the best of our knowledge, this is the first report of a cystic PanNET in a patient with NF-1.

\section{Karger'=}


Case Reports in
Gastroenterology

Case Rep Gastroenterol 2021;15:108-114

DOI: $10.1159 / 000510210$

(c) 2021 The Author(s). Published by S. Karger AG, Basel www.karger.com/crg

Shinozaki et al.: PanNET Complicated by Neurofibromatosis Type 1

\section{Statement of Ethics}

Informed consent was obtained from the participant involved in the study.

\section{Conflict of Interest Statement}

The authors have no conflicts of interest to declare.

\section{Funding Sources}

None.

\section{Author Contributions}

Hiroharu Shinozaki and Satoshi Shinozaki drafted and wrote the manuscript. Yuuichi Sasakura and Toshiaki Terauchi acquired the data. Junichi Matsui, Kenji Kobayashi, Alan Kawarai Lefor, and Yoshiro Ogata revised it critically for important intellectual content. All authors read and approved the final version of the manuscript.

\section{References}

1 Viskochil D, Buchberg AM, Xu G, Cawthon RM, Stevens J, Wolff RK, et al. Deletions and a translocation interrupt a cloned gene at the neurofibromatosis type 1 locus. Cell. 1990 Jul;62(1):187-92.

2 Hirbe AC, Gutmann DH. Neurofibromatosis type 1: a multidisciplinary approach to care. Lancet Neurol. 2014 Aug;13(8):834-43.

3 Walker L, Thompson D, Easton D, Ponder B, Ponder M, Frayling I, et al. A prospective study of neurofibromatosis type 1 cancer incidence in the UK. Br J Cancer. 2006 Jul;95(2):233-8.

4 Mussi C, Schildhaus HU, Gronchi A, Wardelmann E, Hohenberger P. Therapeutic consequences from molecular biology for gastrointestinal stromal tumor patients affected by neurofibromatosis type 1 . Clin Cancer Res. 2008 Jul;14(14):4550-5.

5 Ito T, Tanaka M, Sasano H, Osamura YR, Sasaki I, Kimura W, et al.; Neuroendocrine Tumor Workshop of Japan. Preliminary results of a Japanese nationwide survey of neuroendocrine gastrointestinal tumors. J Gastroenterol. 2007 Jun;42(6):497-500.

6 Jensen RT, Berna MJ, Bingham DB, Norton JA. Inherited pancreatic endocrine tumor syndromes: advances in molecular pathogenesis, diagnosis, management, and controversies. Cancer. 2008 Oct;113(7 Suppl):180743.

7 Gottfried ON, Viskochil DH, Couldwell WT. Neurofibromatosis Type 1 and tumorigenesis: molecular mechanisms and therapeutic implications. Neurosurg Focus. 2010 Jan;28(1):E8.

8 Coskey RL, Tranquada RE. INSULINOMA AND MULTIPLE NEUROFIBROMATOSIS: REPORT OF A CASE. Metabolism. 1964 Apr;13(4):312-8.

9 Saurenmann P, Binswanger R, Maurer R, Stamm B, Hegglin J. [Somatostatin-producing endocrine pancreatic tumor in Recklinghausen's neurofibromatosis. Case report and literature review]. Schweiz Med Wochenschr. 1987 Jul;117(30):1134-9.

10 Fung JW, Lam KS. Neurofibromatosis and insulinoma. Postgrad Med J. 1995 Aug;71(838):485-6.

11 Thannberger P, Wilhelm JM, Derragui A, Saraceni O, Kieffer P. [Von Recklinghausen's disease associated with pancreatic somatostatinoma]. Presse Med. 2001 Nov;30(35):1741-3.

12 Fujisawa T, Osuga T, Maeda M, Sakamoto N, Maeda T, Sakaguchi K, et al. Malignant endocrine tumor of the pancreas associated with von Recklinghausen's disease. J Gastroenterol. 2002 Jan;37(1):59-67.

\section{Karger'=}




\section{Case Reports in Gastroenterology}

13 Perren A, Wiesli P, Schmid S, Montani M, Schmitt A, Schmid C, et al. Pancreatic endocrine tumors are a rare manifestation of the neurofibromatosis type 1 phenotype: molecular analysis of a malignant insulinoma in a NF-1 patient. Am J Surg Pathol. 2006 Aug;30(8):1047-51.

14 Nishi T, Kawabata Y, Hari Y, Imaoka H, Ishikawa N, Yano S, et al. A case of pancreatic neuroendocrine tumor in a patient with neurofibromatosis-1. World J Surg Oncol. 2012 Jul;10(1):153.

15 Rogers A, Wang LM, Karavitaki N, Grossman AB. Neurofibromatosis Type 1 and pancreatic islet cell tumours: an association which should be recognized. QJM. 2015 Jul;108(7):573-6.

16 Dąbkowski K, Kos-Kudła B, Andrysiak-Mamos E, Syrenicz A, Pilch-Kowalczyk J, Starzyńska T. Cystic pancreatic neuroendocrine tumours - a gastroenterologist's point of view. Endokrynol Pol. 2018;69(3):3205.

17 Cloyd JM, Kopecky KE, Norton JA, Kunz PL, Fisher GA, Visser BC, et al. Neuroendocrine tumors of the pancreas: degree of cystic component predicts prognosis. Surgery. 2016 Sep;160(3):708-13.

18 Tanaka M, Fernández-Del Castillo C, Kamisawa T, Jang JY, Levy P, Ohtsuka T, et al. Revisions of international consensus Fukuoka guidelines for the management of IPMN of the pancreas. Pancreatology. 2017 Sep Oct;17(5):738-53.

19 Morales-Oyarvide V, Yoon WJ, Ingkakul T, Forcione DG, Casey BW, Brugge WR, et al. Cystic pancreatic neuroendocrine tumors: the value of cytology in preoperative diagnosis. Cancer Cytopathol. 2014 Jun;122(6):435-44.
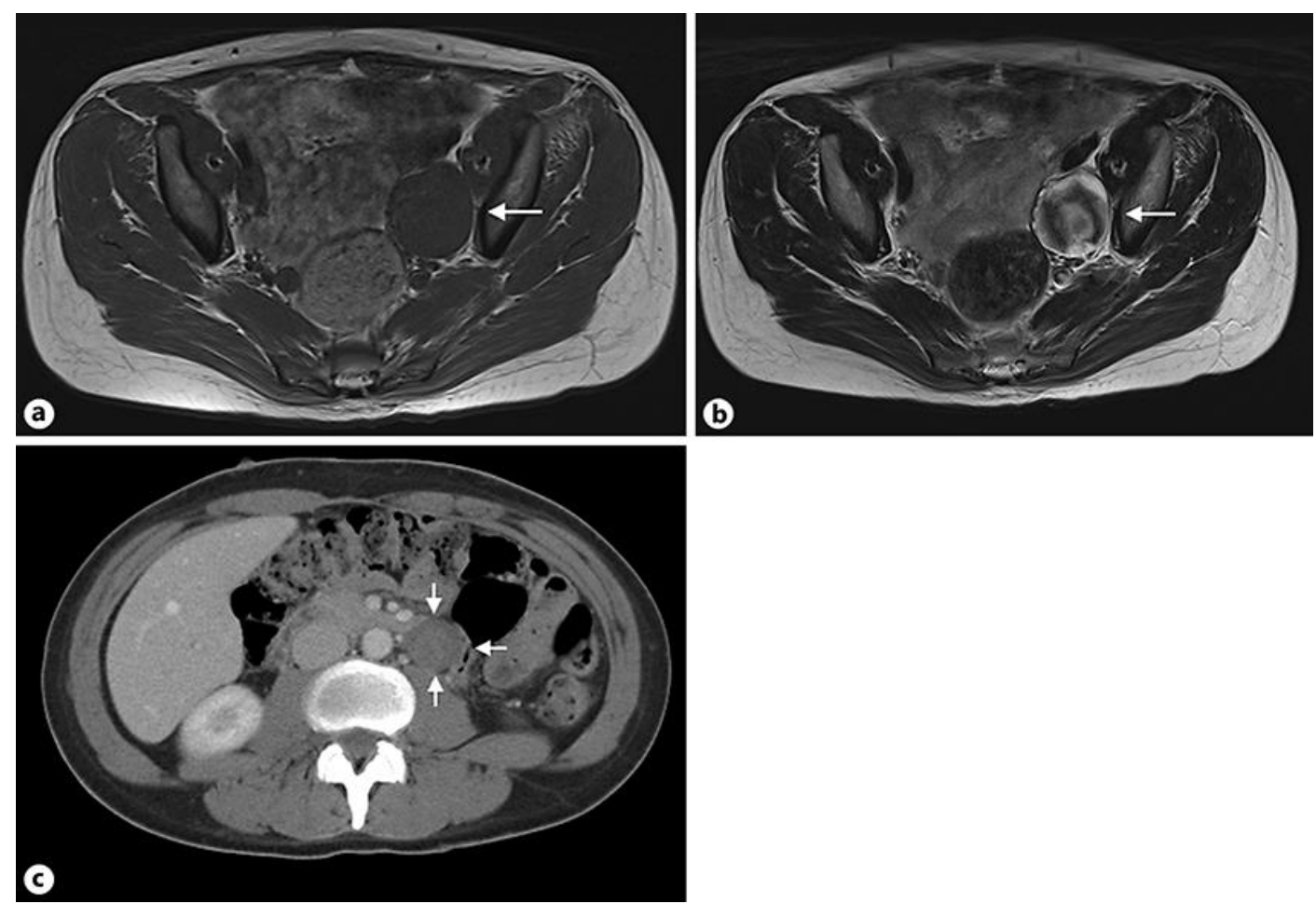

Fig. 1. a T1-weighted magnetic resonance imaging shows a solid pelvic mass with low intensity, $30 \times 50 \times$ $60 \mathrm{~mm}$ in diameter, located between the left external iliac artery and the iliopsoas muscle (arrow). b T2weighted imaging shows mixed intensity (arrow). c Computed tomography scan shows a para-aortic mass, $30 \times 20 \mathrm{~mm}$ in diameter (arrows).

\section{Karger'=}




\section{Case Reports in Gastroenterology}
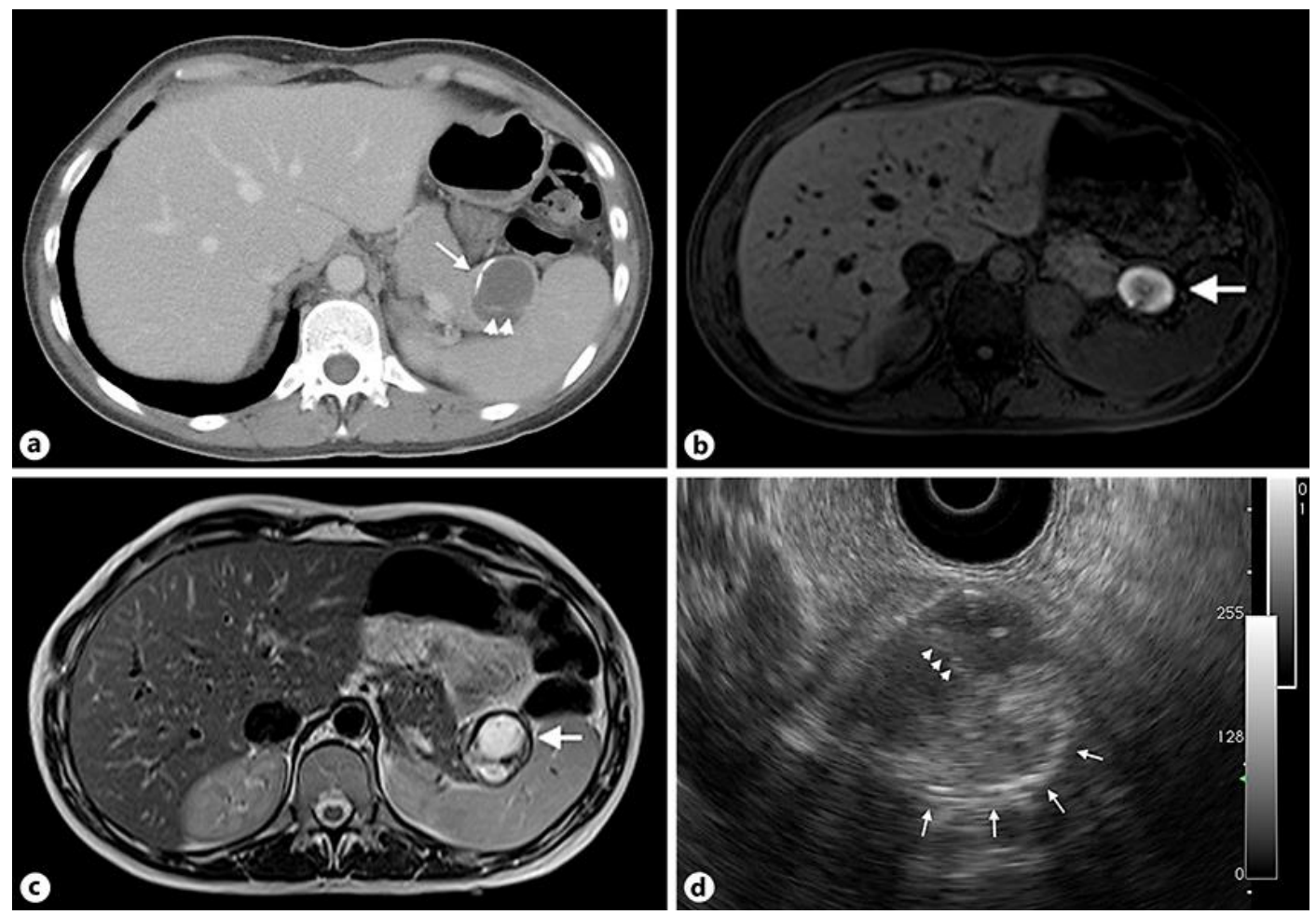

Fig. 2. Cystic tumor in the tail of the pancreas: contrast-enhanced computed tomography scan shows 32$\mathrm{mm}$ cystic tumor with calcifications at the edge (arrow) and a septum (arrowheads) (a); T1-weighted magnetic resonance imaging also shows a cystic tumor with marginally high intensity (arrow) (b); T2weighted imaging shows a low intensity capsule and septum in the cystic tumor (arrow) (c); endoscopic ultrasonography shows 32-mm cystic lesion with calcified capsule (arrows), internal septum (arrowheads) and focal hyperechoic lesion in the tumor, suggestive of intratumor necrosis and bleeding (d). 


\section{Case Reports in Gastroenterology}
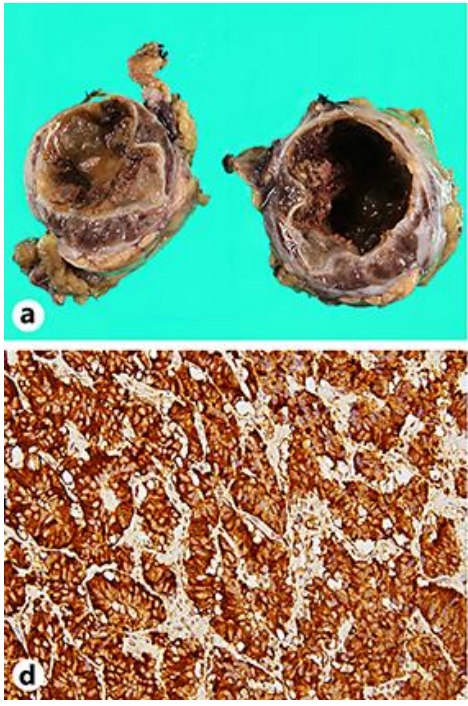
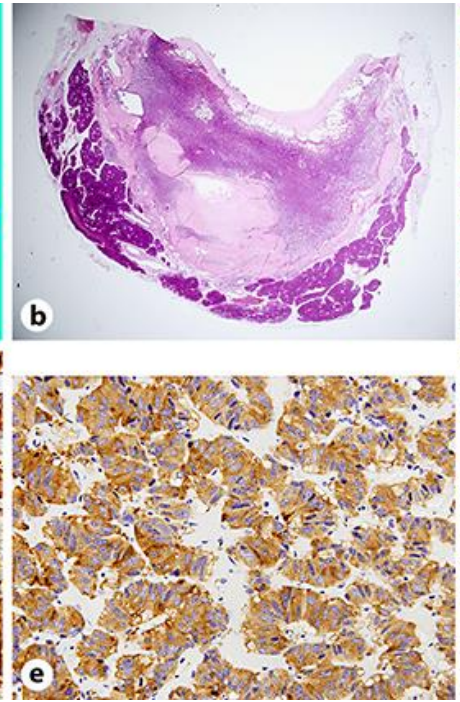
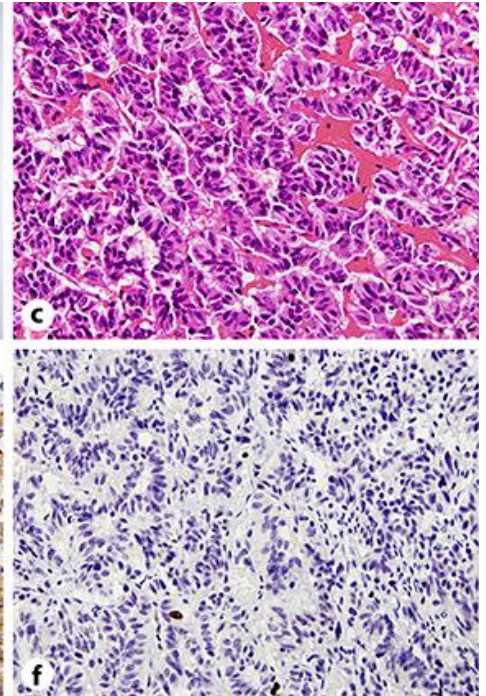

Fig. 3. Surgical specimen of the pancreatic cystic tumor: $45 \times 40 \mathrm{~mm}$ tumor encloses septum and brown necrotic contents (a); loupe view of the tumor (b); cord and ribbon-like proliferation of differently sized atypical cells $(\times 40$, hematoxylin and eosin) (c); positive chromogranin A staining $(\times 40)(\mathrm{d})$; positive synaptophysin staining $(\times 40)($ e); Ki-67 index $<1 \%$ and mitotic count $1 / 10$ high power field indicate a grade G1 neuroendocrine tumor (World Health Organization category) (f).
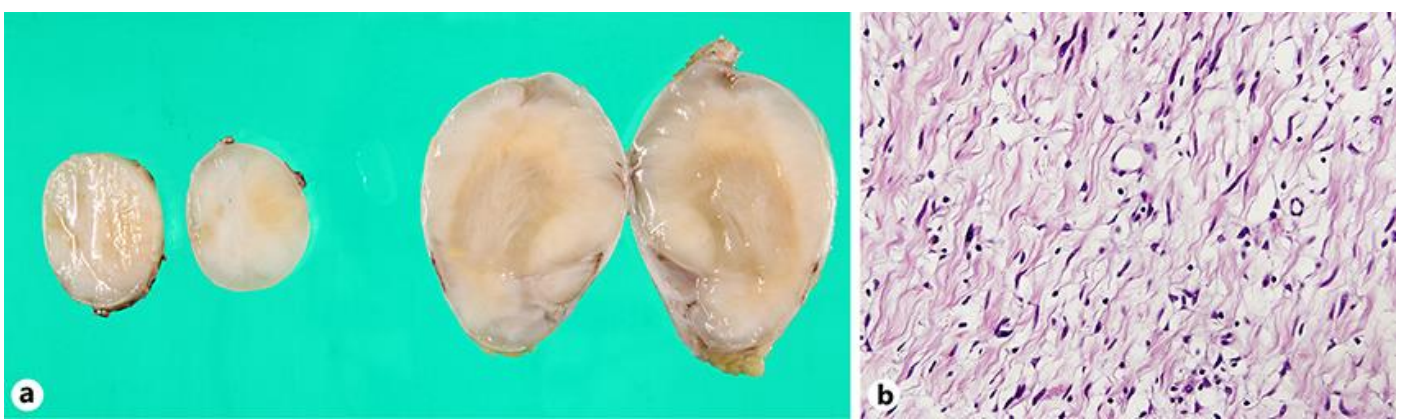

Fig. 4. Surgical specimens of the abdominal neurofibromas: macroscopic view, left 3-cm para-aortic tumor and right 6-cm pelvic tumor (a); microscopic view: spindle cell configurations and collagen bundles (magnification $\times 40$, hematoxylin and eosin) (b). 